\title{
Plasma-enhanced chemical vapor deposition of low- loss as-grown germanosilicate layers for optical waveguides
}

Feridun Ay Sedat Agan Atilla Aydinli 


\title{
Plasma enhanced chemical vapor deposition of low loss as-grown germanosilicate layers for optical waveguides
}

\author{
Feridun $\mathrm{Ay}^{a}$, Sedat $\mathrm{Agan}^{b}$, Atilla Aydinli ${ }^{a}$ \\ ${ }^{a}$ Department of Physics, Bilkent University, 06800 Ankara, Turkey; \\ ${ }^{b}$ Department of Physics, Kirikkale University, 71450 Kirikkale, Turkey
}

\begin{abstract}
We report on systematic growth and characterization of low-loss germanosilicate layers for use in optical waveguides. Plasma enhanced chemical vapor deposition (PECVD) technique was used to grow the films using silane, germane and nitrous oxide as precursor gases. Chemical composition was monitored by Fourier transform infrared (FTIR) spectroscopy. N-H bond concentration of the films decreased from $0.43 \times 10^{22} \mathrm{~cm}^{-3}$ down to below $0.06 \times 10^{22} \mathrm{~cm}^{-3}$, by a factor of seven as the $\mathrm{GeH}_{4}$ flow rate increased from 0 to $70 \mathrm{sccm}$. A simultaneous decrease of $\mathrm{O}-\mathrm{H}$ related bonds was also observed by a factor of 10 in the same germane flow range. The measured $\mathrm{TE}$ loss rates at $\lambda=632.8 \mathrm{~nm}$ were found to increase from are $0.20 \pm 0.02$ to $6.46 \pm 0.04 \mathrm{~dB} / \mathrm{cm}$ as the germane flow rate increased from 5 to $50 \mathrm{sccm}$, respectively. In contrast, the propagation loss values for TE polarization at $\lambda=1550 \mathrm{~nm}$ were found to decrease from $0.32 \pm 0.03$ down to $0.14 \pm 0.06 \mathrm{~dB} / \mathrm{cm}$ for the same samples leading to the lowest values reported so far in the literature, eliminating the need for high temperature annealing as is usually done for these materials to be used in waveguide devices.
\end{abstract}

Keywords: PECVD, germanosilicate, FTIR, optical loss, prism coupling, optical waveguides

\section{INTRODUCTION}

Silicon based dielectric materials have attracted a lot of attention in recent years for applications integrated optics. Among them germanosilicate films $\left(\mathrm{SiO}_{x}: \mathrm{Ge}\right.$ or $\left.\left(\mathrm{SiO}_{2}\right)_{x}:\left(\mathrm{GeO}_{2}\right)_{1-x}\right)$ attract special interest due to their excellent compatibility with single mode fibers. ${ }^{1}$ Planar waveguides using germane as the core dopant and silica as substrate ensure excellent compatibility with the existing fiber technology. Furthermore, second-harmonic generation and $^{2}$ and significant UV photosensitivity ${ }^{3}$ have already been shown in germanosilicate waveguides, providing great potential for optical applications. ${ }^{4}$

Among the methods conventionally used for growth of planar germanosilicate layers are; sol-gel methods, ${ }^{1}$ RF sputtering, ${ }^{2}$ powder melting ${ }^{5,6}$ and plasma enhanced chemical vapor deposition (PECVD) techniques. ${ }^{4}$ Asdeposited $\mathrm{SiO}_{x}$ :Ge optical waveguides grown with these methods all share the shortcoming of having relatively large propagation losses at wavelengths of $632.8 \mathrm{~nm}$ and $1.55 \mu \mathrm{m}$. In particular, loss at $\lambda=1.55 \mu \mathrm{m}$ is known to be caused mainly by $\mathrm{N}-\mathrm{H}$ and $\mathrm{O}-\mathrm{H}$ bonds incorporated into the film matrix while loss at $632.8 \mathrm{~nm}$ is mainly due to scattering mechanisms. ${ }^{7}$ The reported values for propagation losses range between $3.5-10 \mathrm{~dB} / \mathrm{cm}^{1,3}$ at $\lambda=632.8 \mathrm{~nm}$ and are larger than $2 \mathrm{~dB} / \mathrm{cm}$ at $\lambda=1.55 \mu \mathrm{m},{ }^{8}$ although not being analyzed systematically. To reduce the mentioned loss values, it is common practice to anneal the as-grown layers at temperatures as high as $1100{ }^{0} \mathrm{C}$ for prolonged times $.1,9$ Recently, Zhang et al. ${ }^{9}$ reported chemical vapor deposition (CVD) grown germanosilicate planar waveguides with propagation losses of about 2 and $1 \mathrm{~dB} / \mathrm{cm}$ at wavelengths of 632.8 and $1550 \mathrm{~nm}$, respectively. However, due to low index contrast, almost half of the mode power in those waveguides propagates in the cladding material the effect of which is not taken into account in the reported loss values.

This report concentrates on systematic growth and characterization of as-grown germanosilicate planar waveguides. The layers were grown by standard PECVD technique by using silane, germane and nitrous oxide as precursor gases. As a result of the analysis we were able to identify that increasing the germane flow rate leads to decreasing of the hydrogen related bonds and thus to decreasing of the propagation loss at $\lambda=1.55 \mu \mathrm{m}$, with the lowest reported values.

Further author information: (Send correspondence to A.A.)

A.A.: E-mail: aydinli@fen.bilkent.edu.tr, Telephone: +90 312290 1579,

web-site: http://www.fen.bilkent.edu.tr/ iogroup/

F.A.: E-mail: ay@fen.bilkent.edu.tr 


\section{EXPERIMENTAL}

Parallel-plate type Plasmalab 8510C PECVD reactor was used for the growth of germanosilicate layers. The samples were grown at $350{ }^{\circ} \mathrm{C}$, in a pressure of 1 torr and $\mathrm{RF}$ power of $10 \mathrm{~W}$ at a frequency of $13.56 \mathrm{MHz}$, applied to plates with a diameter of $24 \mathrm{~cm}$. Silane $\left(2 \% \mathrm{SiH}_{4} / \mathrm{N}_{2}\right)$ and nitrous oxide $\left(\mathrm{N}_{2} \mathrm{O}\right)$ gas flow rates were kept constant at 180 and $225 \mathrm{sccm}$, while that of germane $\left(2 \% \mathrm{GeH}_{4} / \mathrm{He}\right)$ has been varied between 0 and 70 sccm. The films used for FTIR characterization were grown on high resistivity silicon wafers with both sides polished and thicknesses between 1.5 and $2.5 \mu \mathrm{m}$. The compositional analysis of the germanosilicate films were done by making use of Bomem H\&B Series Fourier transform infrared (FTIR) spectrometer. The spectra were obtained in the 5500-250 $\mathrm{cm}^{-1}$ range with $8 \mathrm{~cm}^{-1}$ resolution. The refractive index of the films were measured by prism coupling technique ${ }^{10}$ at $\lambda=632.8 \mathrm{~nm}$ and $1550 \mathrm{~nm}$ and the film thicknesses were determined by the same method and by stylus profilometry.

\section{RESULTS AND DISCUSSIONS}

\subsection{Compositional Analysis}

As the $\mathrm{GeH}_{4}$ flow rate was increased from 5 to $50 \mathrm{sccm}$, the refractive index of the layers was measured to vary between 1.4683 and $1.5189( \pm 0.0002)$ for $\mathrm{TE}$ and between 1.4681 and 1.5191 for TM polarized light at $\lambda=632.8$ $\mathrm{nm}$ (see Fig. 1). At $\lambda=1550 \mathrm{~nm}$ the corresponding refractive indices were measured to vary between 1.4530 1.5033 and 1.4527-1.5032 for TE and TM polarizations, respectively. The growth rate of the films increased gradually from 370 to $440 \AA / \mathrm{min}$ with increasing $\mathrm{GeH}_{4}$ flow rate.

Eight samples s0-s7 with corresponding $\mathrm{GeH}_{4}$ flow rates of 0 (i.e. $\mathrm{SiO}_{x}$ ), 5, 10, 20, 30, 50, 60, and $70 \mathrm{sccm}$ were used for compositional characterization. Normalized absorbance spectra of the samples in $250-1500 \mathrm{~cm}^{-1}$ range are shown in Fig. 2. All the samples show a dominant absorption feature around $1050 \mathrm{~cm}^{-1}$ which can be resolved into $\mathrm{Si}-\mathrm{O}$ symmetric and asymmetric stretching and $\mathrm{Ge}-\mathrm{O}$ stretching vibrations ${ }^{11,12}$ at frequencies of about 1065, 1150 and $980 \mathrm{~cm}^{-1}$, respectively. Si-O rocking and bending vibrations were identified at $\sim 450$ and $\sim 820 \mathrm{~cm}^{-1}$, while $\mathrm{Ge}-\mathrm{O}$ and $\mathrm{Ge}-\mathrm{H}$ bending vibrations were observed at $\sim 420$ and $\sim 650 \mathrm{~cm}^{-1}$, respectively. Analysis of the oxygen bond concentration was performed by integrating over the relevant bands. The bands were decomposed using nonlinear curve fitting, assuming that the peaks are in the form of symmetric Gaussians. The results of this analysis are plotted in Fig. 3. The normalized integrated absorption $\left.\left(\int_{\text {band }} \alpha(\omega) d \omega\right)\right)$ of the

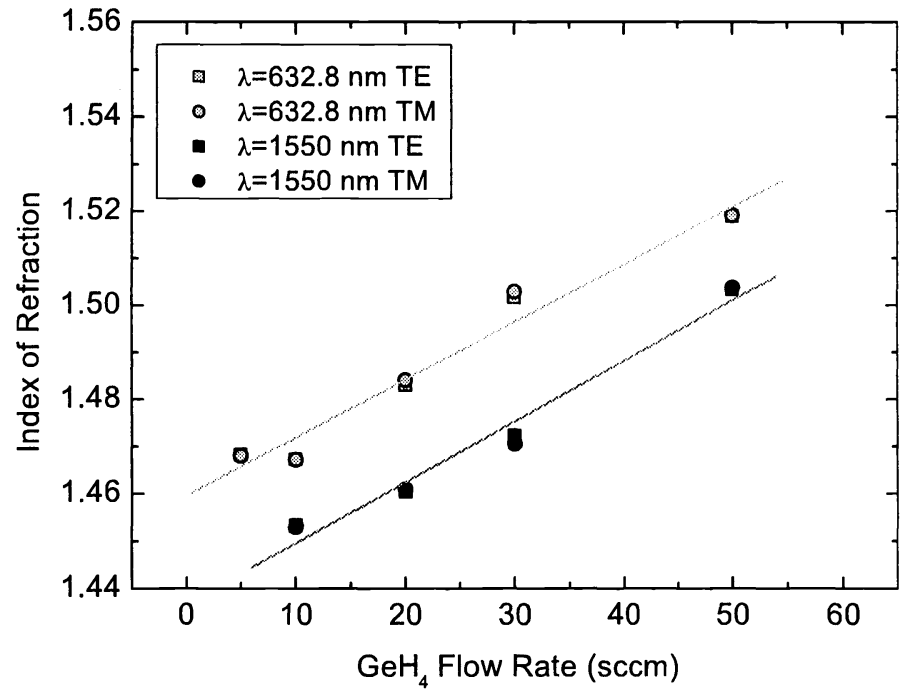

Figure 1. Variation of the index of refraction for germanosilicate layers with $\mathrm{GeH}_{4}$ flow rate at $\lambda=632.8$ and $1550 \mathrm{~nm}$ for both TE and TM polarizations. 


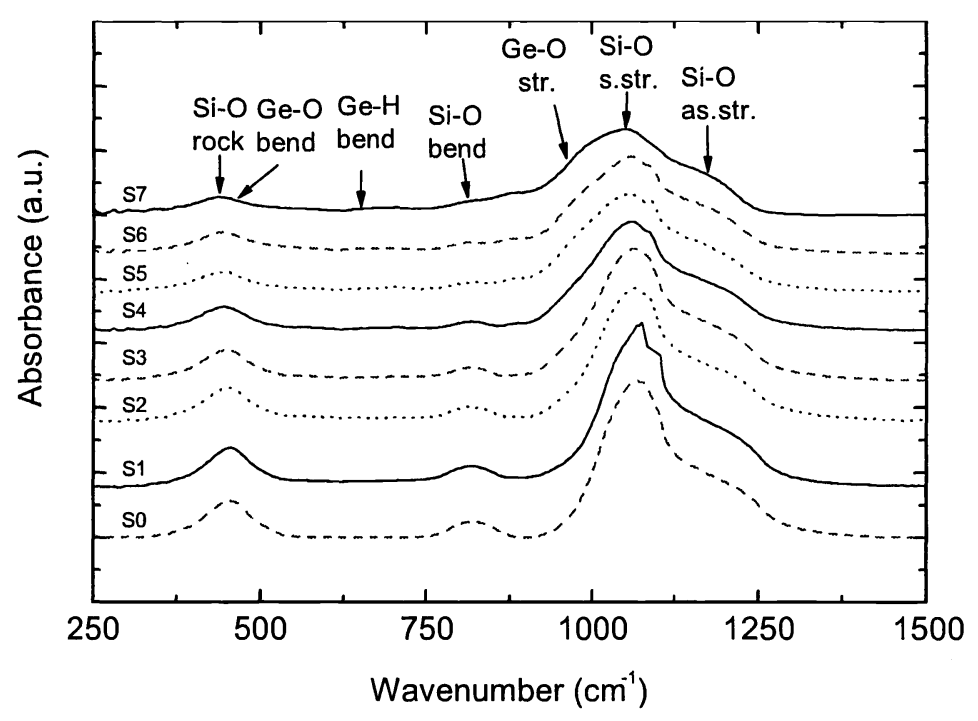

Figure 2. FTIR absorption spectra of the samples at 250-1550 $\mathrm{cm}^{-1}$ range with the the following $\mathrm{GeH}_{4}$ flow rates; s0:0, s1:5, s2:10, s3:20, s4:30, s5:50, s6:60 and s7:70 sccm.

$\mathrm{Si}-\mathrm{O}$ bonds exhibited a gradual decrease while that of $\mathrm{Ge}-\mathrm{O}$ bonds showed a steady increase as a function of germane flow rate. Both reached saturation at a $\mathrm{GeH}_{4}$ flow rate of about $50 \mathrm{sccm}$. Assuming that the infrared absorption cross section for the bonds of interest are similar, it can be stated that $\mathrm{Si}$ and Ge are incorporated into the film matrix at nearly equal concentrations for $\mathrm{GeH}_{4}$ flow rate of $50 \mathrm{sccm}$ and larger.

The most striking result of the FTIR analysis was that the observed amount of both $\mathrm{N}-\mathrm{H}$ and $\mathrm{O}-\mathrm{H}$ bonds decreased with increasing $\mathrm{GeH}_{4}$ flow rate (see Fig. 4). The $\mathrm{N}-\mathrm{H}$ stretching vibrations were observed at $\sim 3380$ $\mathrm{cm}^{-1}$, GeO-H stretching vibrations at $\sim 3470$ and $\sim 3515 \mathrm{~cm}^{-1}$, and finally SiO-H stretching vibrations at $\sim 3600$

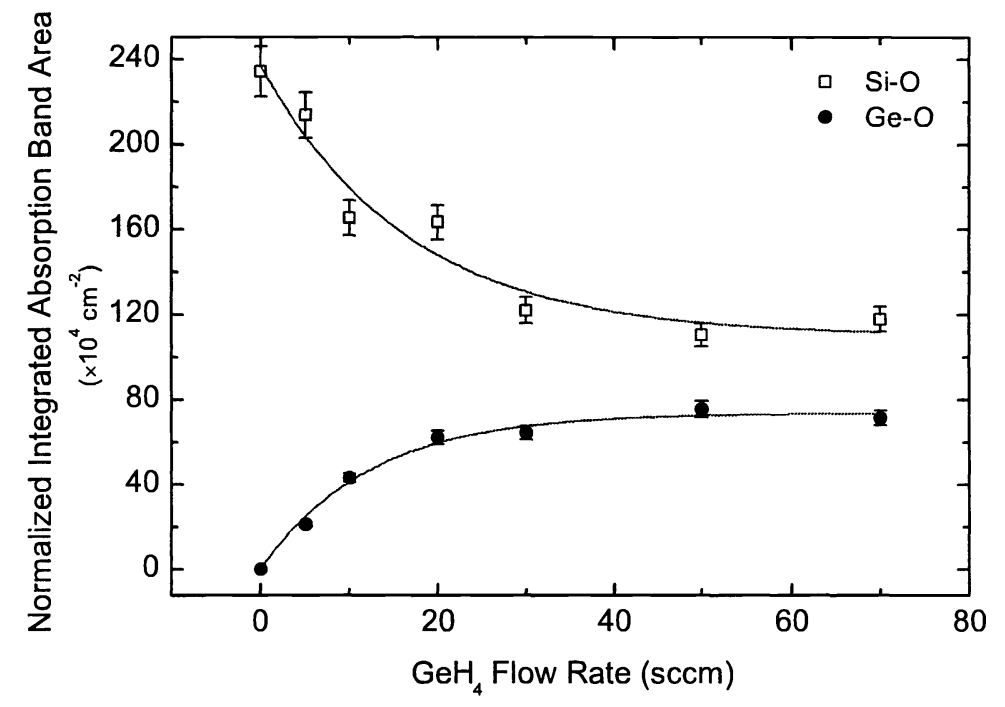

Figure 3. Variation of normalized absorption band area for $\mathrm{Si}-\mathrm{O}$ and $\mathrm{Ge}-\mathrm{O}$ related bonds with increasing $\mathrm{GeH}_{4}$ flow rate. 


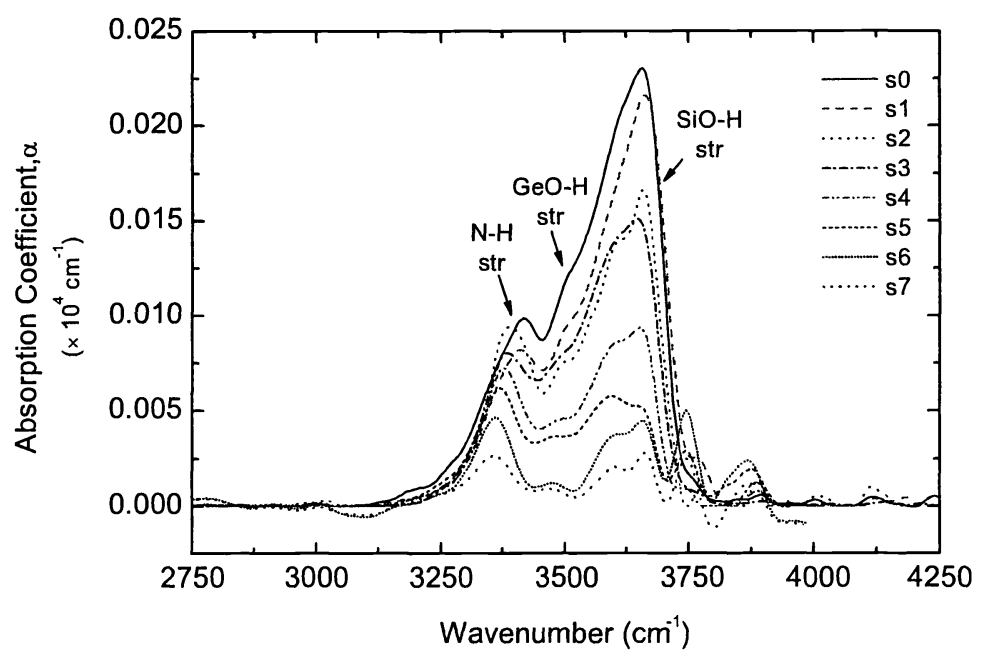

Figure 4. FTIR absorption coefficient $(\alpha)$ vs wavenumber for the germanosilicate samples in the $\mathrm{N}-\mathrm{H}$ and $\mathrm{O}-\mathrm{H}$ absorption band region.

and $\sim 3665 \mathrm{~cm}^{-1}{ }^{6}$ As the $\mathrm{GeH}_{4}$ flow rate in the grown samples increased, the $\mathrm{N}-\mathrm{H}$ stretching vibrational frequency shifted about $30 \mathrm{~cm}^{-1}$ towards lower frequencies, while that of $\mathrm{GeO}-\mathrm{H}$ and $\mathrm{SiO}-\mathrm{H}$ remained constant. The $\mathrm{N}-\mathrm{H}$ and $\mathrm{O}-\mathrm{H}$ bond concentrations were calculated for all the grown layers by using the method of Lanford and Rand ${ }^{13}$ For N-H bonds, the absorption cross section value of $\sigma_{N-H}=5.3 \times 10^{-18} \mathrm{~cm}^{2}$ was used throughout the calculations. The corresponding value for $\mathrm{O}-\mathrm{H}$ bonds, was $\sigma_{O-H}=1.5 \times 10^{-21} \mathrm{~cm}^{2}$, obtained by Rostaing et al. ${ }^{14}$ In spite of the relatively large uncertainty for the $\mathrm{O}-\mathrm{H}$ bond absorption cross section, we believe that the results obtained can be safely used in the comparison of $\mathrm{O}-\mathrm{H}$ bond concentrations of the samples. For other quantities such as peak wavenumber $(\omega)$, full width at half maximum (FWHM), and normalized absorption band area $\left(\int \alpha d \omega\right)$, of each absorption band we estimate typical uncertainty values of $\pm 5 \mathrm{~cm}^{-1}, \pm 5 \mathrm{~cm}^{-1}$, and \pm $4 \%$, respectively. The results of the calculations are plotted in Fig.5. As seen from the figure, the N-H bond

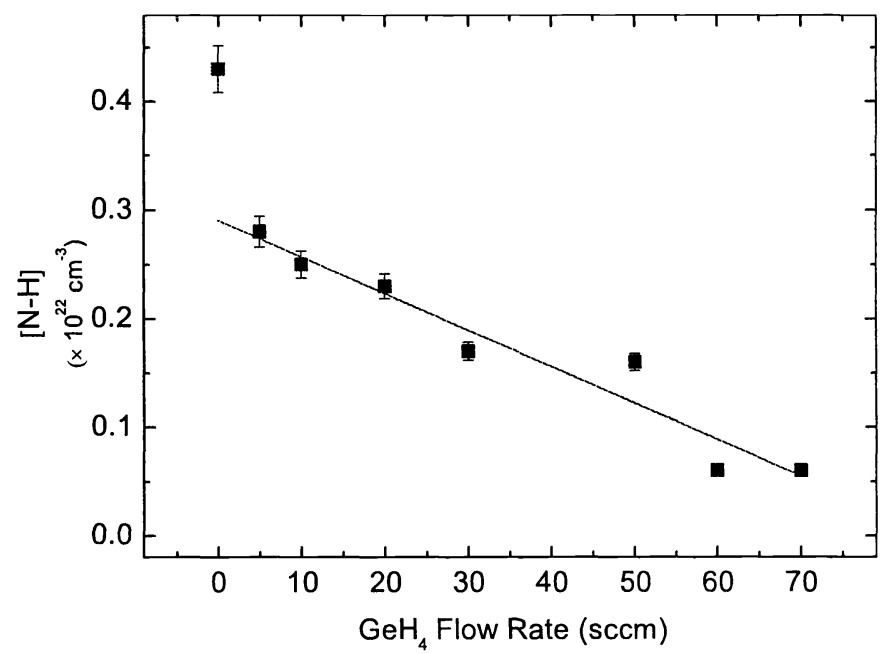

Figure 5. Variation of calculated $\mathrm{N}-\mathrm{H}$ bond concentrations for germanosilicate samples with increasing $\mathrm{GeH}_{4} \mathrm{flow}_{\mathrm{rate}}$ 
Table 1. N-H bond str. concentration calculations for germanosilicate films by using FTIR transmittance spectroscopy.

\begin{tabular}{|c|c|c|c|c|c|}
\hline $\begin{array}{c}\mathrm{GeH}_{4} \text { Flow Rate } \\
(\mathrm{sccm})\end{array}$ & $\begin{array}{c}\text { Central Frequency } \\
\left(\mathrm{cm}^{-1}\right)\end{array}$ & $\begin{array}{c}\text { FWHM } \\
\left(\mathrm{cm}^{-1}\right)\end{array}$ & $\begin{array}{c}\alpha_{\max } \\
\left(\mathrm{cm}^{-1}\right)\end{array}$ & $\begin{array}{c}\text { Sum of Norm. Band Area } \\
\left(\times 10^{4} \mathrm{~cm}^{-2}\right)\end{array}$ & $\begin{array}{c}\text { Concentration } \\
\left(\times 10^{22} \mathrm{~cm}^{-3}\right)\end{array}$ \\
\hline 0 (oxide) & 3433 & 229 & 93 & 5.23 & 0.43 \\
\hline 5 & 3416 & 176 & 80 & 3.44 & 0.28 \\
\hline 10 & 3395 & 132 & 92 & 3.00 & 0.25 \\
\hline 20 & 3392 & 145 & 78 & 2.79 & 0.23 \\
\hline 30 & 3380 & 126 & 69 & 2.13 & 0.17 \\
\hline 50 & 3370 & 139 & 61 & 2.07 & 0.06 \\
\hline 60 & 3357 & 101 & 29 & 0.71 & 0.06 \\
\hline 70 & 3353 & 124 & 25 & 0.75 & \\
\hline
\end{tabular}

concentration has decreased from $0.43 \times 10^{22} \mathrm{~cm}^{-3}$ down below our detection limit of $0.06 \times 10^{22} \mathrm{~cm}^{-3}$, by a factor of seven as the $\mathrm{GeH}_{4}$ flow rate increased from 0 (silicon oxide) to $70 \mathrm{sccm}$. The details of the analysis are summarized in Table 1.

As for the $\mathrm{O}-\mathrm{H}$ bonds, their concentration showed a sharp decrease, as well from about $2.27 \times 10^{22} \mathrm{~cm}^{-3}$ down to $0.23 \times 10^{22} \mathrm{~cm}^{-3}$, by a factor of ten in the same germane flow range. The observed decrease of these bonds has an important impact on propagation losses at $\lambda=1.55 \mu \mathrm{m}$ of the waveguides grown using germanosilicate films.

\subsection{Loss Analysis}

The waveguide propagation losses at $\lambda=632.8$ and $1550 \mathrm{~nm}$ were measured by using prism coupling technique. ${ }^{15}$ The germanosilicate core layers were grown on oxidized silicon wafers with $\mathrm{SiO}_{2}$ thickness of $9.8 \mu \mathrm{m}$, serving as lower cladding. Core layer thicknesses were varied between $4-6 \mu \mathrm{m}$, by using the same parameters as the samples used in FTIR characterization. At $\lambda=1.55 \mu \mathrm{m}$ the moving prism method was used, in which light was coupled into the waveguide at different lengths and the output power was monitored at the end of the slab waveguide. At $\lambda=632.8 \mathrm{~nm}$ the method of Ramponi et al. ${ }^{16}$ was employed, in which a single prism and measurement of reflected and transmitted light are used to determine the propagation losses. In order to compare the propagation losses of our films, care must be taken to take the confinement factor of each waveguide into account. Depending on the index contrast and thicknesses of the layers, some fraction of the total time averaged power travels in the core layer of the waveguide and the remaining power propagates in the cladding layer.

This issue can be overcome by normalizing the measured loss to identical predetermined fraction of the total power propagating in the core layer. With this approach, loss values of germanosilicate planar waveguides with different index contrast and thicknesses can be compared to each other. In this work, the fraction of power travelling in the guiding layer was chosen to be same as in the waveguides studied by Zhang et al.. ${ }^{9}$ The results of the loss analysis for three representative waveguides grown with different germane flow rates are summarized in Table 2.

For purpose of completeness, raw values of the measured loss rates for TE polarization at $\lambda=1.55 \mu \mathrm{m}$ are 0.55 $\pm 0.06,0.37 \pm 0.10$ and $0.27 \pm 0.11 \mathrm{~dB} / \mathrm{cm}$ for the samples $\mathrm{s} 1$, s2 and s5, respectively. The measured propagation

Table 2. Propagation loss variation with $\mathrm{GeH}_{4}$ flow rate for three representative germanosilicate waveguides at $\lambda=632.8$ and $1550 \mathrm{~nm}$.

\begin{tabular}{|c|c|c|c|c|c|}
\hline & $\begin{array}{c}\mathrm{GeH}_{4} \text { flow } \\
\text { rate }\end{array}$ & \multicolumn{4}{|c|}{$\begin{array}{c}\text { Propagation loss } \\
(\mathrm{dB} / \mathrm{cm})\end{array}$} \\
\hline & & \multicolumn{2}{|c|}{$632.8 \mathrm{~nm}$} & \multicolumn{2}{c|}{$1550 \mathrm{~nm}$} \\
\hline S1 & $5 \mathrm{sccm}$ & $0.20 \pm 0.02$ & $0.11 \pm 0.11$ & $0.32 \pm 0.03$ & $0.22 \pm 0.04$ \\
\hline S2 & $10 \mathrm{sccm}$ & $0.34 \pm 0.17$ & $0.26 \pm 0.15$ & $0.22 \pm 0.06$ & $0.18 \pm 0.02$ \\
\hline S5 & $50 \mathrm{sccm}$ & $6.46 \pm 0.04$ & $6.47 \pm 0.04$ & $0.14 \pm 0.06$ & $0.18 \pm 0.07$ \\
\hline
\end{tabular}

Proc. of SPIE Vol. $5451 \quad 515$ 
loss values at $\lambda=632.8 \mathrm{~nm}$ for the same samples at TE polarization are $0.20 \pm 0.02,0.34 \pm 0.17$, and $6.46 \pm 0.04$ $\mathrm{dB} / \mathrm{cm}$, respectively. The observed trend of propagation loss increase at $\lambda=632.8 \mathrm{~nm}$ is similar with the results available in the literature. Specifically, as the Ge content of the layers increase the propagation loss increases as well due mainly to scattering mechanisms. ${ }^{3,17}$ As for the propagation loss values at $\lambda=1.55 \mu \mathrm{m}$, they are in agreement with our expectations based on FTIR analysis. The normalized propagation loss rates showed a decrease by a factor of two, while approaching our measurement limit, and following the decreasing $\mathrm{N}-\mathrm{H}$ bond concentration.

\section{CONCLUSIONS}

We have grown germanosilicate layers using the PECVD technique. Compositional analysis using FTIR spectroscopy showed that the amount of $\mathrm{N}-\mathrm{H}$ and $\mathrm{O}-\mathrm{H}$ related bonds exhibited a drastic decrease with increasing $\mathrm{GeH}_{4}$ flow rate. Planar waveguides fabricated with germanosilicate core layers showed the lowest propagation

loss values reported so far both for as deposited and annealed layers at $\lambda=1.55 \mu \mathrm{m},{ }^{9,18}$ eliminating the need for costly and cumbersome annealing process.

\section{ACKNOWLEDGMENTS}

The authors acknowledge the support of Bilkent University (Research Fund Code: Phys-03-02).

\section{REFERENCES}

1. D. G. Chen, B. G. Potter, J. H. Simmons, " $\mathrm{GeO}_{2}-\mathrm{SiO}_{2}$ thin films for planar waveguide applications," J. Non-Cryst. Solids 178, pp.135-147, 1994.

2. O. Sugihara, M. Nakanishi, H. Fujimura, C. Egami, N. Okamoto, "Thermally poled silicate thin films with large second-harmonic generation," J. Opt. Soc. Am. B 15, pp. 421-425, 1998.

3. D. C. M. P. D. G. K. S. Potter, B. G. Potter, "Novel process for the production of large, stable photosensitivity in glass films," Appl. Phys. Lett. 68, pp. 2011-2013, 1996.

4. R.A. Jarvis, J.D. Love, A. Durandet, G.D. Conway, R.W. Boswell, "UV-induced index change in hydrogenfree germano-silicate waveguides," Electron. Lett. 32, pp. 550-552, 1996.

5. Q. Zeng, J.F. Stebbins, A.D. Heaney, T. Erdogan, "Hydrogen speciation in hydrogen-loaded, germaniadoped silica glass: a combined NMR and FTIR study of the effects of UV irradiation and heat treatment," J. Non-Cryst. Solids 258, pp. 78-91, 1999.

6. V.G. Plotnichenko, V.O. Sokolov, E.M. Dianov, "Hydroxyl groups in germanosilicate glasses," J. Non-Cryst. Solids 278, pp. 85-98, 2000.

7. B. S. Sahu, O. P. Agnihotri, S. C. Jain, R. Mertens, I. Kato, "Influence of hydrogen on losses in silicon oxynitride planar optical waveguides," Semicond. Sci. Tech. 15, pp. L11-L14, 2000.

8. D. Moss, J. Canning, M. Bazylenko, "Bragg gratings in hollow-cathode PECVD germanosilica planar waveguides ," Conference on Lasers and Electro-Optics Technical Digest, p. 245, OSA, Washington DC, 1998.

9. Q. Y. Zhang, K. Pita, C. K. F. Ho, N. Q. Ngo, L. P. Zuo, S. Takahashi, "Low optical loss germanosilicate planar waveguides by low-pressure inductively coupled plasma-enhanced chemical vapor deposition," Chem. Phys. Lett. 368, pp. 183-188, 2003.

10. P. K. Tien, "Light waves in thin films and integrated optics," Appl. Optics 10, pp. 2395-2313, 1971.

11. Y. P. Chou and S. C. Lee, "Structural, optical, and electrical properties of hydrogenated amorphous silicon germanium alloys," J. Appl. Phys. 83, pp. 4111-4123, 1998.

12. G. Lucovsky, S. S. Chao, J. Yang, J. E. Tyler, R. C. Ross, W. Czubatyj, "Chemical bonding of hydrogen and oxygen in glow-discharge -deposited thin films of $a$-Ge:H and $a$-Ge:(H,O)," Phys. Rev. B 31, pp. 2190-2197, 1985.

13. W. A. Lanford and M. J. Rand, "The hydrogen content of plasma-deposited silicon nitride," J. Appl. Phys. 49, pp. 2473-2477, 1978.

14. J. C. Rostaing, Y. Cross, S. C. Gujrathi, S. Poulain, "Quantitative infrared characterization of plasma enhanced CVD silicon oxynitride films," J. Non-Cryst. Solids 97-98, pp. 1051-1054, 1987. 
15. S. Agan, F. Ay, A. Aydinli, "Stress effects in prism coupling measurements of thin polymer films," Appl. Phys. A: Materials Science \& Processing, accepted for publication, 2004.

16. R. Ramponi, R. Osellame, M. Marangoni, "Two straightforward methods for the measurement of optical losses in planar waveguides," Rev. Sci. Instrum. 73, pp. 1117-1120, 2002.

17. T. Kominato, Y. Ohmori, N. Takato, H. Okazaki, M. Yasu, "Ring resonators composed of $\mathrm{GeO}_{2}$-doped silica waveguides ," J. Lightwave Technol. 10, pp. 1781-1788, 1992.

18. F. Ay, A. Aydinli, S. Agan, "Low-loss as-grown germanosilicate layers for optical waveguides," Appl. Phys. Lett. 83, pp. 4743-4746, 2003. 